\title{
Stereotactic ablative radiotherapy and systemic treatments for extracerebral oligometastases, oligorecurrence, oligopersistence and oligoprogression from lung cancer
}

Manon Kissel ${ }^{1,2^{*}}$ (D), Isabelle Martel-Lafay ${ }^{3}$, Justine Lequesne ${ }^{4}$, Jean-Christophe Faivre ${ }^{5}$, Cécile Le Péchoux ${ }^{2}$, Dinu Stefan ${ }^{1}$, Victor Barraux ${ }^{1}$, Cédric Loiseau', Jean-Michel Grellard ${ }^{4}$, Serge Danhier ${ }^{1}$, Delphine Lerouge ${ }^{1}$, Christos Chouaid $^{6}$, Radj Gervais ${ }^{1}$ and Juliette Thariat ${ }^{1}$

\begin{abstract}
Background: Stereotactic irradiation (SBRT) is a standard of care for inoperable stage I lung cancer and brain oligometastases from lung cancer but is controversial for extracranial oligometastases. We assessed outcomes of lung cancer patients with extracranial metastases in oligometastatic, oligorecurrent, oligopersistent and oligoprogressive settings ("oligometastatic spectrum") under strategies using SBRT +/- systemic treatments.

Methods: A retrospective multicentric study of consecutive lung cancer adult patients with 1-5 extracranial metastases treated with SBRT was conducted.

Results: Of 91 patients (99 metastases, median age 63,64.8\% adenocarcinomas, 19.8\% molecular alterations), 11\% had oligometastases, $49.5 \%$ oligorecurrence, $19.8 \%$ oligopersistence and $19.8 \%$ oligoprogression. Of 36\% of patients under systemic treatments at initiation of SBRT, systemic treatment interruption was performed in $58 \%$ of them. With median follow up of 15.3 months, crude local control at irradiated metastases was 91\%, while median distant progression-free survival (dPFS) and overall survival were 6.3 and 28.4 months (2-year survival 54\%). Initial nodal stage and oligometastatic spectrum were prognostic factors for APFS; age, initial primary stage and oligometastatic spectrum were prognostic factors for survival on multivariate analysis. Patients with oncogene-addicted tumors more frequently had oligoprogressive disease. Repeat ablative irradiations were preformed in $80 \%$ of patients who had oligorelapses. Worst acute toxicities consisted of 5.5\% and one late toxic death occurred.

Conclusion: The oligometastatic spectrum is a strong prognosticator in patients undergoing SBRT for extracranial metastases. Median survival was over two years but dPFS was about 6 months. Continuation of systemic therapy in oligoprogressive patients should be investigated.
\end{abstract}

Keywords: Lung cancer, Oligometastasis, Stereotactic radiotherapy, Systemic treatment, Survival

\footnotetext{
* Correspondence: manon.kissel@gustaveroussy.fr

${ }^{1}$ Centre de lutte contre le cancer François Baclesse/ ARCHADE, radiotherapy

department, 3 avenue du Général Harris, 14000 Caen, France

${ }^{2}$ Institut Gustave Roussy, radiotherapy department, 114 Rue Edouard Vaillant,

94800 Villejuif, France

Full list of author information is available at the end of the article
}

(c) The Author(s). 2019 Open Access This article is distributed under the terms of the Creative Commons Attribution 4.0 International License (http://creativecommons.org/licenses/by/4.0/), which permits unrestricted use, distribution, and reproduction in any medium, provided you give appropriate credit to the original author(s) and the source, provide a link to the Creative Commons license, and indicate if changes were made. The Creative Commons Public Domain Dedication waiver (http://creativecommons.org/publicdomain/zero/1.0/) applies to the data made available in this article, unless otherwise stated. 


\section{Background}

Lung cancer is the primary cause of death from cancer among men and second leading cause among women, both in France and worldwide. This is primarily due to propensity for metastases. However, metastatic disease appears to harbor different prognoses that are dependent on tumor bulk and kinetics. In particular, oligometastatic disease describes an intermediate state between local disease and multimetastatic cancer. This change of paradigm and prognosis has been integrated into the 8th lung cancer TNM classification [1]. However, proper estimates of the prevalence of oligometastatic lung cancer patients would require consistent definition of oligometastatic disease, accurate description of disease in databases and clinical trials (which include various metastatic disease bulks) and full diagnostic work up. Rough estimates suggest that single metastasis be present in $7 \%$ of patients but drops to only 1\% using Positron Emission Tomography (TEP-TDM) [2, $3]$. As a consequence, it has been difficult to address the question of a potential benefit of aggressive ablative treatments in oligometastatic lung cancer [4]. Surgical removal of adrenal, cerebral or pulmonary metastases have long been performed for lung cancer patients but may not be appropriate for all metastatic sites and in case of several synchronous metastases. On the other hand, first line platin-based doublet yields low response rates [5]. Similarly, $20 \%$ of patients have a targetable genetic alteration and can exhibit dramatic tumor response but acquired resistance is usually unavoidable within about a year. Thus, therapeutic options were limited before the recent rise of immunotherapy. Immunotherapy may however be limited by PD1/PDL1 expression and has only been available since 2017. Altogether, systemic therapies alone may not be optimal in disease settings, such as oligometastatic lung cancer, where long term control can be expected. Recent retrospective data suggest that lung metastases from various primaries may benefit from various combinations of stereotactic ablation and systemic treatments that can be personalized based on disease progression and number of metastases [6]. Recent prospective data also suggest that consolidative stereotactic irradiation improves survival in primarily polymetastatic lung cancers that have been downstaged to oligometastatic stage after chemotherapy [7]. Thus, consistent with the standard role of stereotactic irradiation in inoperable lung primaries and brain oligometastases from lung primaries, the use of stereotactic irradiation in oligometastases (any extracranial site) from lung primaries might provide a survival benefit. Yet, series on extracranial metastases from lung cancer are still rare.

The goal of our retrospective observational multicentric study was to assess practice patterns of stereotactic irradiation and outcomes of consecutive lung cancer patients with limited metastatic disease in the " oligo spectrum ».

\section{Methods}

This retrospective study was institutional review-board, INDS (Institut National des Données de Santé), CEREES (Comité d'Expert pour les Recherches, les Etudes et les Evaluations dans le domaine de la Santé) and CNIL (Commission Nationale de l'Informatique et des Libertés) -approved. Patients over 18 were included after ablative stereotactic irradiation on all extracranial oligometastatic lesions (one to five) from their lung cancer in the following situations of the oligometastatic spectrum: oligometastases at diagnosis, oligorecurrence defined as oligometastatic relapse after primary, oligopersistence defined as stable residual disease sites after systemic treatment and oligoprogression in a polymetastatic context with progressive lesions while all other lesions are controlled with systemic treatment (Fig. 1) [6, 8]. Stereotactic irradiation had to be performed between January 2012 and August 2016. Patients with cerebral metastases controlled for at least 3 months before extracranial stereotactic irradiation were allowed. Any systemic treatment was allowed.

Clinical evaluation with a radiation oncologist was planned before and after treatment and weekly during the treatment. Surveillance was carried out with clinical exams and regular CT-scans. Therapeutic response evaluation (with central review assessment) was made using RECIST 1.1 criteria. Toxicity severity was reported utilizing CTCAE (Common Terminology Criteria for Adverse Events) scale, version 4.0. Data included treated sites, technical data (doses, fractionation, prescription modalities) and outcomes.

\section{Statistics}

Qualitative variables were described by using numbers and percentages, and quantitative variables by using mean (+/ - standard deviation) or median and range in case of non-normal distribution. Overall survival, local and distant recurrence-free survival curves were estimated by the Kaplan-Meier method and calculated from the beginning of stereotactic irradiation. The median time and survival rates at different points since the treatment start were estimated with their 95\% confidence interval. The log-rank test and the Cox model were used to compare survival curves according to observed characteristics. The effect of continuous variables on survival was evaluated both continuously and through a log-rank test by dichotomizing the variable either by the median value or by a so-called optimal cut-off value, i.e., the one producing the most significant statistical difference in survival between the two groups thus defined.

\section{Results}

Population description

Ninety-one (99 treated lesions) patients were included. Patients' characteristics are reported in (Table 1). Briefly, 

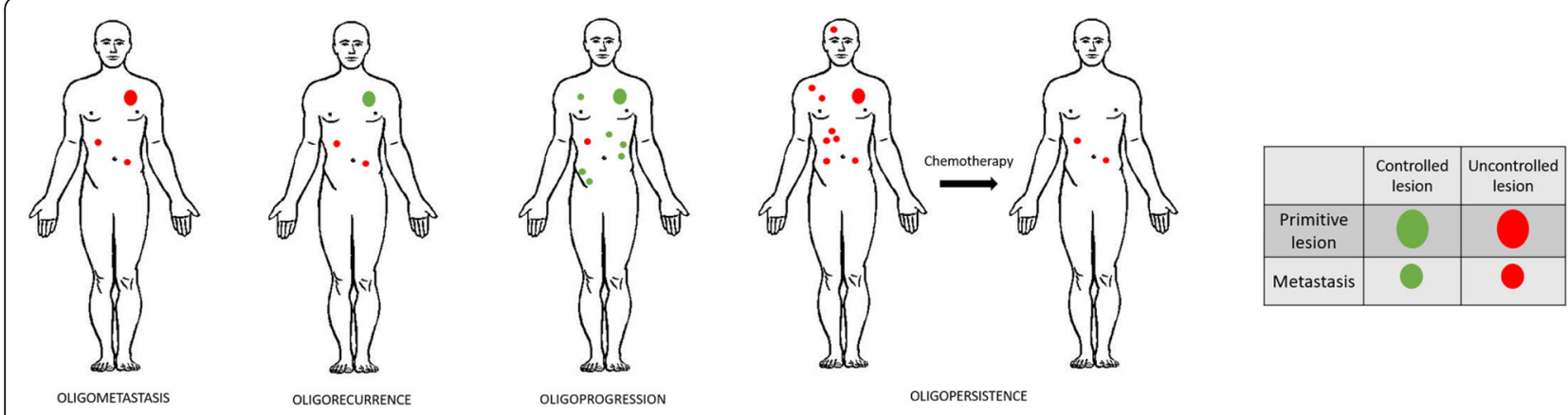

Fig. 1 definition of oligometastatic spectrum

$64.8 \%$ of patients had adenocarcinomas and $19.8 \%$ had molecular alterations.

Histological verification of at least one metastatic lesion was available in $20 \%$ of cases. Among the 8 patients treated for two lesions, one patient was biopsied on both metastatic sites. All other patients were classified as M1a, according to TNM 8th, due to metastatic lymph node or another distant lesion. Overall, $91.2 \%$ had a single metastasis. Eleven percent had oligometastases, 49.5\% oligorecurrence, $19.8 \%$ residual stable disease (for irradiated as consolidative therapy) and 19.8\% oligoprogression. Adrenal metastases were present in $27.3 \%$ of the patients, lung in $21.2 \%$, bone in $20.2 \%$, liver and spine both in $12.1 \%$ and lymph nodes in $7.1 \%$.

Prior other local treatments had been performed in $30 \%$ of patients (surgery of primary or metastatic lesion, radiochemotherapy of the primary, radiofrequency, cryotherapy). $35 \%$ of the patients never had any systemic treatment. Stereotactic irradiation was performed during first line for $42 \%$ of patients, second line for $10 \%$ of patients and third line or more for $13 \%$ of patients.

\section{Technical data}

Patients were treated with Cyberknife (Accuray) in the 4 participating centers and some patients (5 cases) with NovalisTx $^{\text {TM }}$ (Varian $^{\oplus}$, Palo Alto, California, USA and BrainLAB AG, Munich, Germany) in one center and with Synergy $^{\circ}$ (Elekta) in one center (6 cases). Total dose ranged between 15 to $60 \mathrm{~Gy}$ in 2 to 8 fractions. Total median dose was $39 \mathrm{~Gy}$ for a biological equivalent dose (BED) of $60.5 \mathrm{~Gy}$ on tumor $(\alpha / \beta 10)$. Median dose per fraction was $8 \mathrm{~Gy}$. Prescription schemes were heterogeneous, the most common being $3 \times 15$ Gy, $5 \times 7$ Gy and $5 \times 8$ Gy. For lung lesions, the most frequent scheme was $4 \times 12.5 \mathrm{~Gy}$. For liver lesions, the preferred scheme was $3 \times 15$ Gy. For adrenal metastases, a 5 to 6 fractions of 7 Gy was preferred.

Isodose of prescription was the 80 and $90 \%$ with the Cyberknife $^{\circledast}$ or Novalis ${ }^{\mathrm{Tm}}$, respectively.

Treatment was delivered in 12 days for a single lesion in average, 33 days for two lesions. Mean GTV was 7 $\mathrm{cm}^{3}$ and PTV $26 \mathrm{~cm}^{3}$.

\section{Outcomes}

Median follow-up was 15.3 months.

\section{Toxicity}

Worst acute toxicities consisted of $5.5 \%$ grade 3 , mostly as pain or fatigue. One patient experienced necrosis leading to major pain during adrenal irradiation (GTV $25 \mathrm{cc} ; 5 \times 7$ Gy with Cyberknife $^{\odot}$ ), requiring treatment interruption. Another patient with adrenal oligometastasis treated with Novalis ${ }^{\mathrm{TM}}$ (PTV $80 \mathrm{cc} ; 5 \times 7.5 \mathrm{~Gy}$ ) had an abscess, a septicemia, requiring antibiotics and drainage.

Late toxicities consisted of grade 1-2 neuropathic pain, without fracture after spinal radiation in $13 \%$ of patients. Grade 1-2 pneumonitis occurred in $8 \%$ of patients. No grade 3 or 4 toxicity was noted. Nevertheless, one toxic death occurred following stereotactic irradiation of a sphenoidal lesion (further to osteo-meningeal breach, meningitis, and septic shock).

\section{Local response}

Best local response was evaluated for each irradiated lesion: objective response rate at irradiated sites was $91 \%$ including complete response in $44 \%$, partial response in $27 \%$, stable in $20 \%$ and progression in $9 \%$ (Fig. 2). Local response was significantly better when GTV was less than $3 \mathrm{cc}: p=0.008, \mathrm{HR}=0.263[0.088 ; 0.789]$ and PTV less than $18.5 \mathrm{cc}: p=0.008, \mathrm{HR}=0.264$ [0.088; 0.795]. Dose, protraction and metastatic site were not associated with local response.

\section{Distant progression-free survival}

Median distant progression-free survival (dPFS) was 6.3 months [4; 8.1] (Fig. 2). In multivariate analysis, initial nodal status and oligometastatic spectrum (Fig. 1) were predictive of dPFS (Table 2). Median dPFS was 7.8 months for node-negative patients and 3.9 months for nodepositive patients: $p=0.035$; $\mathrm{HR}=1.714$ [1.012; 2.903]. Oligoprogressive patients had the worst dPFS. Better dPFS was associated with prolonged free interval, with a threshold of 2 years: $p=0.001 ; \mathrm{HR}=2.405$ [1.282; 4.509] only on univariate analysis. Among the 68 patients who had out of 
Table 1 Patient, tumor and treatment characteristics

\begin{tabular}{|c|c|c|c|}
\hline & $\mathrm{n}$ & $\%$ & $N$ \\
\hline & médiane & {$[\min -\max ]$} & \\
\hline Center & & & 91 \\
\hline$C F B$ & 16 & $17.6 \%$ & \\
\hline$C L B$ & 40 & $44 \%$ & \\
\hline$I C L$ & 28 & $30.8 \%$ & \\
\hline$I G R$ & 7 & $7.7 \%$ & \\
\hline Age & 63.43 & {$[42.39-87.34]$} & 91 \\
\hline Gender & & & 91 \\
\hline$F$ & 33 & $36.3 \%$ & \\
\hline M & 58 & $63.7 \%$ & \\
\hline PS & & & 90 \\
\hline 0 & 39 & $43.3 \%$ & \\
\hline 1 & 43 & $47.8 \%$ & \\
\hline 2 & 8 & $8.9 \%$ & \\
\hline Smoker (current or former) & 73 & $85.9 \%$ & 85 \\
\hline Respiratory comorbidity & 26 & $29.2 \%$ & 89 \\
\hline Cardiovascular comorbidity & 24 & $27.3 \%$ & 88 \\
\hline Other cancer history & 19 & $21.6 \%$ & 88 \\
\hline Other significant comorbidity & 21 & $23.9 \%$ & 88 \\
\hline Histology & & & 91 \\
\hline Adenocarcinoma & 59 & $64.8 \%$ & \\
\hline Squamous cell & 16 & $17.6 \%$ & \\
\hline Small Cell Lung Cancer & 8 & $8.8 \%$ & \\
\hline Other & 8 & $8.8 \%$ & \\
\hline Molecular alteration & 18 & $19.8 \%$ & 91 \\
\hline EGFR & 8 & $9 \%$ & \\
\hline$A L K$ & 2 & $2.2 \%$ & \\
\hline KRAS & 4 & $4.5 \%$ & \\
\hline HER2 & 2 & $2.3 \%$ & \\
\hline CMET amplification & 1 & $1.1 \%$ & \\
\hline CMET mutation & 1 & $1.1 \%$ & \\
\hline $\mathrm{T}$ & & & 89 \\
\hline$T 1$ & 18 & $20.2 \%$ & \\
\hline$T 2$ & 35 & $39.3 \%$ & \\
\hline T3 & 25 & $28.1 \%$ & \\
\hline T4 & 11 & $12.4 \%$ & \\
\hline $\mathrm{N}$ & & & 89 \\
\hline NO & 31 & $34.8 \%$ & \\
\hline N1 & 16 & $18 \%$ & \\
\hline N2 & 26 & $29.2 \%$ & \\
\hline N3 & 14 & $15.7 \%$ & \\
\hline$N x$ & 2 & $2.2 \%$ & \\
\hline Pre-therapeutic PET-TDM & 79 & $87.8 \%$ & 90 \\
\hline Metastase(s) operability & & & 91 \\
\hline
\end{tabular}

Table 1 Patient, tumor and treatment characteristics (Continued)

\begin{tabular}{|c|c|c|}
\hline & $n$ & $\%$ \\
\hline & médiane & [min-max] \\
\hline Yes & 7 & $7.7 \%$ \\
\hline No & 41 & $45.1 \%$ \\
\hline Not reported & 43 & $47.3 \%$ \\
\hline Controlled primitive lesion & 77 & $84.6 \%$ \\
\hline \multicolumn{3}{|l|}{ Number of metastase(s) } \\
\hline 1 & 83 & $91.2 \%$ \\
\hline$>=2$ & 8 & $8.8 \%$ \\
\hline
\end{tabular}

Metachronous $63 \quad 69.2 \%$

$\begin{array}{lll}\text { Synchronous } & 28 & 30.8 \%\end{array}$

Indication

Oligopersistance $\quad 18 \quad 19.8 \%$

Oligometastatic $\quad 10 \quad 11 \%$

Oligoprogression $\quad 18 \quad 19.8 \%$

Oligorecurrence $\quad 45 \quad 49.5 \%$

Treated site

99

$\begin{array}{lll}\text { Liver } & 12 & 12.1 \%\end{array}$

Lymph node $\quad 7 \quad 7.1 \%$

Bone $\quad 20 \quad 20.2 \%$

Lung $\quad 21 \quad 21.2 \%$

$\begin{array}{lll}\text { Spine } & 12 & 12.1 \%\end{array}$

Adrenal $27 \quad 27.3 \%$

$\begin{array}{llll}\text { Contralateral to primitive lesion } & 13 & 48.1 \% & 27\end{array}$

Homolateral to primitive lesion $\quad 14 \quad 51.9 \% \quad 27$

Ongoing systemic treatment before irradiation 91

$\begin{array}{lll}\text { No } & 58 & 63.7 \% \\ \text { Yes } & 33 & 36.3 \%\end{array}$

Systemic treatment interruption during irradiation

No $\quad 1 \quad 2.9 \%$

Yes $\quad 32 \quad 97.1 \%$

CFB Centre François Baclesse, CLB Centre Léon Bérard, ICL Institut de Cancérologie de Lorraine, IGR Institut Gustave Roussy

field relapse, 51\% $(N=35)$ had oligorelapses and 35\% more than one oligorelapse. Of these, $44 \%$ of oligorelapses occurred in the same organ as at first relapse. Overall, $80 \%$ of patients had at least more than one local treatment and $70 \%$ of the patients underwent ablative treatments for all their subsequent oligorelapses.

\section{Overall survival}

Forty-nine patients had died by time of last follow-up, among which $73 \%$ of lung cancer-specific death. Median overall survival was 28.2 months [20.07; 35.5]. Overall survival at 6 months, 1 year and 2 years were respectively 88, 71 and 54\% (Fig. 2). Oligometastatic spectrum 


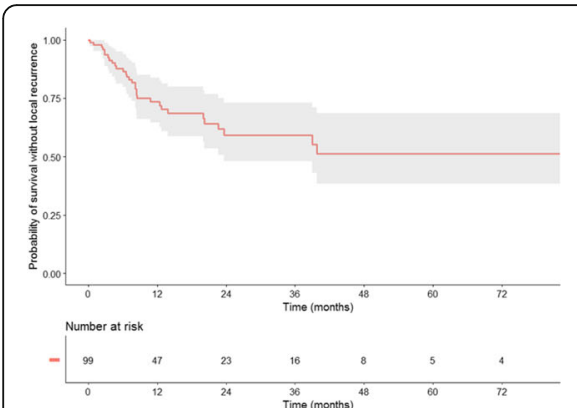

a.

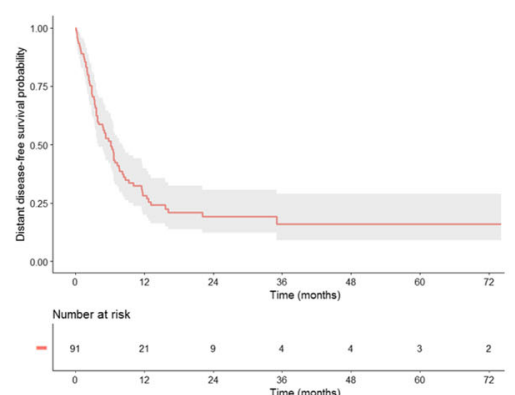

b.

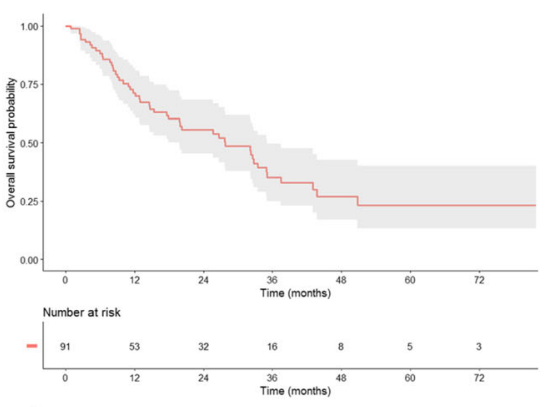

c.

Fig. 2 local control (a), distant progression-free survival (b) and overall survival (c)

(oligometastatic at diagnosis versus oligoprogressive), initial $\mathrm{T}$ stage and younger age were associated with better survival on multivariate analysis. Mean overall survival was 33 months after irradiation of oligorecurrence, 28.2 months after consolidative irradiation and 6.5 months after irradiation of oligoprogression. Median overall survival was not reached in patients with oligometastases at diagnosis (Fig. 3). Metastatic site was associated with survival with patients having spine or lung lesions (versus adrenal or liver lesions) having better survival on univariate analysis (Table 2).
In 18 patients with tumors harboring actionable driver mutations, survival was 34 months [20.4; not reached] versus 27 months $[15.5 ; 43.6]$ in those without mutations $(p=0.581)$. Patients who had at least one major comorbidity had median survival of 28 months $[15.5 ; 38]$ versus 33 months $[20.1$; not reached] in those without comorbidities $(p=0.22)$ (Table 2). For oligorecurrent patients, longer free interval between primary and metastatic spread was associated with better survival, with a threshold of 2 years $(p=0.002)$.

Table 2 prognostic factors of distant progression free survival and overall survival

\begin{tabular}{|c|c|c|c|c|c|c|c|c|}
\hline & \multicolumn{4}{|l|}{ PFS } & \multicolumn{4}{|l|}{ OS } \\
\hline & \multicolumn{3}{|c|}{ Univariate } & \multirow{2}{*}{$\begin{array}{l}\text { Multivariate } \\
p\end{array}$} & \multicolumn{3}{|c|}{ Univariate } & \multirow{2}{*}{$\begin{array}{l}\text { Multivariate } \\
p\end{array}$} \\
\hline & $\overline{H R}$ & IC95 & $p$ & & $\overline{H R}$ & IC95 & $p$ & \\
\hline PET-TDM & & & 0.59 & & 0.44 & {$[0.20,0.94]$} & 0.068 & \\
\hline Oligometastatic site & & & 0.136 & & & & 0.02 & 0.37 \\
\hline Indication (oligometastatic spectrum) (ref = oligometastases) & & & 0.04 & 0.029 & & & 0.03 & 0.02 \\
\hline Center & & & 0.498 & & & & 0.477 & \\
\hline Age $(r e f=>63 y)$ & 0.69 & {$[0.43,1.12]$} & 0.134 & & 0.42 & {$[0.23,0.76]$} & 0.004 & 0.003 \\
\hline Gender (ref = male) & 0.89 & {$[0.55,1.46]$} & 0.65 & & 1.11 & {$[0.62,1.98]$} & 0.731 & \\
\hline Smoking habits & 0.66 & {$[0.34,1.26]$} & 0.226 & & 1.25 & {$[0.53,2.95]$} & 0.593 & \\
\hline Comorbidities & 0.999 & {$[0.61,1.65]$} & 0.992 & & 1.42 & {$[0.78,2.57]$} & 0.223 & \\
\hline Free interval (ref $>516$ days) & 2.41 & {$[1.28,4.51]$} & 0.001 & & 3.23 & {$[1.37,7.61]$} & 0.002 & \\
\hline Primary cancer controlled & 1.24 & {$[0.63,2.44]$} & 0.498 & & 1.14 & {$[0.48,2.70]$} & 0.77 & \\
\hline Number of metastatic lesions $=2(r e f=1)$ & 1.18 & {$[0.53,2.60]$} & 0.695 & & 0.962 & {$[0.38,2.43]$} & 0.928 & \\
\hline Number of previous systemic treatment lines & & & 0.777 & & & & 0.133 & \\
\hline Synchronous lesion (ref = metachronous) & 0.90 & {$[0.53,1.54]$} & 0.716 & & 1.09 & {$[0.60,1.99]$} & 0.779 & \\
\hline Histology & & & 0.985 & & & & 0.685 & \\
\hline EGFR mutation or ALK translocation & 1.56 & {$[0.77,3.15]$} & 0.252 & & 0.83 & {$[0.37,1.85]$} & 0.581 & \\
\hline \multicolumn{9}{|l|}{ Initial T stage $(r e f=T 1)$} \\
\hline $\mathrm{T} 2$ & 1.3 & {$[0.66,2.58]$} & 0.2 & & 1.79 & {$[0.73,4.4]$} & 0.02 & 0.008 \\
\hline T3 & 0.8 & {$[0.39,1.75]$} & & & 0.79 & {$[0.29,2.2]$} & & \\
\hline T4 & 1.9 & {$[0.84,4.5]$} & & & 3 & {$[1.05,8.4]$} & & \\
\hline Initial $\mathrm{N}+$ status $(\mathrm{ref}=\mathrm{N} 0)$ & 1.71 & {$[1.01,2.90]$} & 0.035 & 0.022 & 1.29 & {$[0.69,2.425]$} & 0.411 & \\
\hline
\end{tabular}




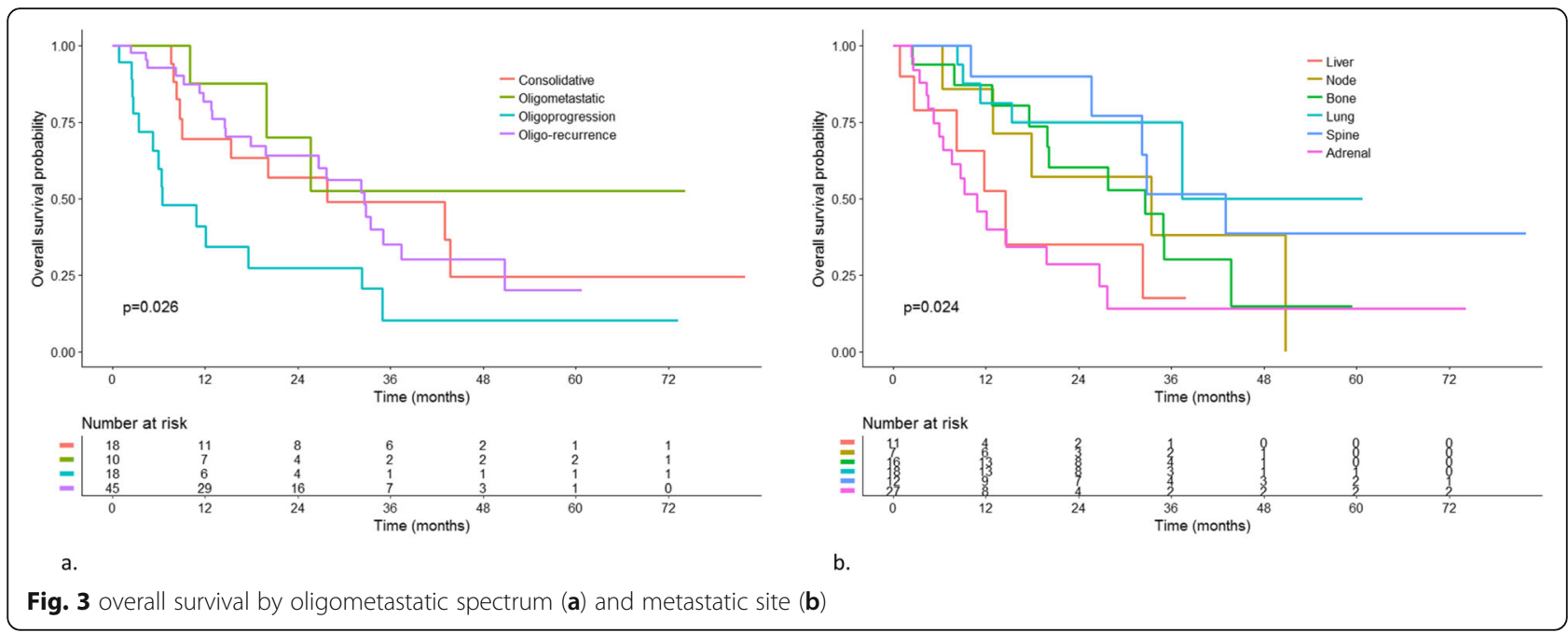

Patients undergoing repeat ablative treatments of their subsequent oligorelapses had a trend for better survival than those with oligorelapses who were not offered ablative treatments $(\mathrm{HR}=0.336[0.114 ; 0.985] p=0.07)$.

\section{Delaying systemic treatment}

At the time of stereotactic irradiation planning, 36\% of the patients were under systemic treatment. Among patients undergoing systemic treatment before radiotherapy, 58\% could be offered treatment pause (until reprogression) that lasted between 1 to 72 months (mean 8.5 months). Among patients who did not have any systemic treatment at the time of stereotactic irradiation, $88 \%$ were treatment-free for 1 to 40 months (mean 11.2 months).

\section{Conclusion}

With 28.2-month overall survival and five-year survival rate of $23 \%$, our results are similar to those of clinical trials involving patients not selected on their response to systemic therapy [9]. In contrast, median distant PFS in our study was 6.3 months i.e. shorter than in these same clinical trial by De Ruysscher et al [9] where median PFS was 12.1 months and 5-year PFS 8\%. The difference might be related to inclusion of oligoprogressive patients in our study, these patients having poorer outcomes compared to oligometastases present at initial diagnosis and treated upfront [6]. As for patient / tumor selection, $91 \%$ of patients had a single metastatic lesion in this French cohort. This is consistent with recruitment in the phase II trial by De Ruysscher et al and may place these patients in a high range of prognosis based on the number of metastases. This however represents a usual bias on the number of metastases in the selection of oligometastatic patients for ablative treatments [10], despite recent data suggesting a benefit in more advanced disease settings [6]. Recent prospective randomized data in favor of stereotactic ablation are however leading to a progressive switch toward more advanced oligometastatic situations $[8,10,11]$. We did include a large spectrum of oligometastatic diseases [6] to address the various situations encountered in routine practice. We showed that these situations are a relevant prognostic classifier with, from best to worst distant progression-free survival and overall survival, oligometastases at first diagnosis, oligorecurrence, oligoconsolidation and oligoprogression. The oligoprogressive group was marked by a particularly mediocre prognosis, with a 6-months median OS. This group is heterogenous since it included pan-negative patients that had a progressive lesion after a first line of platinum-based chemotherapy but also some oncogeneaddicted tumors that progressed slowly after several months of ITK, which probably are very different in terms of tumor phenotype. Patients in this group should be better selected before offering this approach. Because of the low number of patients in this situation in our study one cannot draw conclusions and other studies are needed to identify which patients are on the verge of massive tumor progression and those who indeed have isolated progression. Other prognostic factors for overall survival were age and initial $\mathrm{T}$ status. In contrast to Helou et al, our series was exclusively made of metastases from lung primaries. Among patients who did not have any systemic treatment at the time of stereotactic irradiation, $88 \%$ were treatment-free for 11.2 months in average, suggesting that in patients with indolent disease, systemic treatment interruption may be proposed. In more aggressive situations of the oligometastastatic spectrum, our study was not specifically designed to investigate the impact of systemic treatment interruption during irradiation. However, similar to the study by Helou et al, systemic treatment could be delayed until 
reprogression with the use of ablative stereotactic irradiation. Among patients under systemic treatment at initiation of stereotactic irradiation, 58\% were offered treatment pauses (until reprogression). Time to reprogression indeed varied between 1 and 72 months and median dPFS was 6.3 months. The short distant PFS in our study might reflect dependence on systemic treatment with rapid distant reprogression after interruption of systemic treatments in some patients. Although treatment interruption has been advocated to postpone acquired clonal resistance and to improve the quality of life, such interruption should be cautious in more advanced situations of the oligometastatic spectrum. In patients with driver mutations ( $17 \%$ in our series) who are likely to be addicted to systemic treatments and in patients with oligoprogressive disease (who had the worst dPFS in our series), it may then be more appropriate to combine systemic treatments with stereotactic irradiation. At the time of stereotactic irradiation planning, $36 \%$ of the patients in the current series were under systemic treatment. Toxicity profiles were overall good with $5.5 \%$ grade 3 acute toxicity (with no grade 4-5) and one late toxic death but no grade 3-4 toxicity. Severe toxicity (as well as survival, similar to data by Griffioen et al [12]) was particularly present in patients with adrenal metastases. In addition, the literature suggests that association with EGFR inhibitors do not significantly increase toxicity [13]. Radiosensitization with vemurafenib may require more caution although it has been reported as feasible with stereotactic irradiation [14]. Severe toxicities, such as perforation, have repeatedly been reported with stereotactic irradiation in combination with antiangiogenic agents [15]. Waiting 5 half-lives may not be feasible when oncogenic addiction is suspected or potential disease flare-up outside radiation fields is threatening [16]. Thus, alternate systemic, less toxic, treatments and short radiation courses may be proposed in these patients; or omission of ablative radiotherapy may be questioned in patients carrying targetable molecular abnormalities [17]. EGFR mutation carriers were $13.6 \%$ in our series versus $11-14 \%$ in the literature and ALK rearranged patients $3.4 \%$ versus 5\% [18]. Mutation status was not predictive of better survival unlike in previous reports [7]. Overall survival was good in this group (34 months) but dPFS was low (4 months) and oligoprogression more common. Consistent with data by Weickhardt et al, continuation in oncogene-addicted tumors should probably be recommended in careful combination with ablative therapy [19].

So, why would stereotactic irradiation provide a benefit in a multidisciplinary strategy? The concept behind it is that of mechanical destruction by irradiation of resistant clones while other disease foci are still controlled by systemic treatments. Due to the lack of randomized trials including a stereotactic arm, the demonstration of the level of evidence for extracranial stereotactic irradiation has lagged behind that of intracranial stereotactic irradiation. Despite criticisms of intrinsically better prognosis and immortal time bias in such cohort studies (selection bias where only survivors until SBRT are included, thus inducing a period of time in the OS analysis where the outcome of the study could not occur), there is accumulating randomized evidence of a survival benefit of adding stereotactic to the treatment of oligometastatic disease in NSCLC. Both phases II of Iyengar et al and Gomez et al were closed early because the control group was considered futile since SBRT as a consolidative treatment after first line chemotherapy in oligometastatic patients almost tripled PFS $[7,20]$. SABR COMET multicentric randomized phase II study showed a significant improvement of overall survival in patients treated with SBRT in the oligometastatic or oligorecurrence setting (primary tumor controlled, 18\% of lung cancers included), with a median OS of 41 months versus 26 months in the control arm [21]. Phase III studies CORE and SARON are ongoing [22, 23].

While direct comparisons between metastasectomy, stereotactic irradiation or radiofrequency/cryotherapy will unlikely be conducted [24], all options may be equally valid for single peripheral lung metastases. Stereotactic irradiation is probably less invasive and more appropriate for more complex and advanced oligometastatic disease presentations, such as oligoprogression in several synchronous lesions [6]. Repeatability of local ablative treatments is also of interest. Consistent with a study by Salama et al [25], stereotactic irradiation was performed in $80 \%$ of oligorelapses in our study, and was associated with better survival than in patients with oligorelapses not undergoing stereotactic irradiation. As ablative irradiation may reduce the duration of prescription of expensive drugs such as targeted therapies, antiangiogenics and immunotherapy, it may even have a positive medico-economic impact [26].

This series has the usual biases of retrospective studies and is of relatively small size. It however identified several prognostic groups in the oligometastatic spectrum, in a homogeneous cohort of lung cancer patients. It suggests that personalization of combined therapies based on oligometastatic pattern, oncogene-addiction is warranted. The oligoprogressive indication seems to be the most challenging. More studies are warranted to help clinicians select the patients in this group that might actually benefit from this approach. Some specific studies addressing the issue of oligo-progressive patients are ongoing, of note randomized phases II studies STOPNSCLC (NCT02756793) and HALT (NCT03256981).

\section{Abbreviations}

ALK: Anaplastic Lymphoma Kinase; BED: Biological equivalent dose; CEREES: Comité d'Expert pour les Recherches, les Etudes et les Evaluations dans le domaine de la Santé; CNIL: Commission Nationale de I'Informatique 
et des Libertés; CTCAE: Common Terminology Criteria for Adverse Events; dPFS: Distant Progression-Free Survival; EGFR: Epidermal Growth Factor Receptor; GTV: Gross Tumor Volume; Gy: Gray; HR: Hazard Ratio; INDS: Institut National des Données de Santé; ITK: Inhibitor of Tyrosine Kinase; PDL1: Programmed Death Ligand 1; PFS: Progression Free Survival; PTV: Planning Target Volume; RECIST: Response Evaluation Criteria In Solid Tumours; SBRT: Stereotactic Body Radiation Therapy; TEP-TDM: Positron Emission Tomography - Tomodensitometry

\section{Acknowledgements}

not applicable.

\section{Authors' contributions}

MK: design of the work; acquisition and interpretation of data; article writing. IM-L, JCF and CLP: interpretation of data, article revising. JL: interpretation of data, statistical analysis. DS, CC and RG: design of the work, interpretation of data, article revising. VB and CL: acquisition of data, interpretation of data, article revising. J-MG: design of the work, article revising. SD and DL: article revising. JT: design of the work, interpretation of data, article writing. We state that the manuscript has been read and approved by all authors. This manuscript has not been published and is not under consideration for publication elsewhere.

\section{Funding}

none.

\section{Availability of data and materials}

The datasets used and/or analysed during the current study are available from the corresponding author on reasonable request.

\section{Ethics approval and consent to participate}

yes

This retrospective study was institutional review-board, INDS (Institut National des Données de Santé), CEREES (Comité d'Expert pour les Recherches, les Etudes et les Evaluations dans le domaine de la Santé) and CNIL (Commission Nationale de l'Informatique et des Libertés) -approved.

\section{Consent for publication}

not applicable.

\section{Competing interests}

The authors declare that they have no competing interests.

\section{Author details}

${ }^{1}$ Centre de lutte contre le cancer François Baclesse/ ARCHADE, radiotherapy department, 3 avenue du Général Harris, 14000 Caen, France. ${ }^{2}$ Institut Gustave Roussy, radiotherapy department, 114 Rue Edouard Vaillant, 94800 Villejuif, France. ${ }^{3}$ Centre de lutte contre le cancer Léon Bérard, radiotherapy department, 28 Promenade Léa et Napoléon Bullukian, 69008 Lyon, France. ${ }^{4}$ Centre de lutte contre le cancer François Baclesse, clinical research department, 3 avenue du Général Harris, 14000 Caen, France. ${ }^{5}$ Institut de Cancérologie de Lorraine, radiotherapy department, 6 Avenue de Bourgogne, 54519 Vandœuvre-lès-Nancy, France. ${ }^{6} \mathrm{CHI}$ de Créteil, pneumology department, 40 Avenue De Verdun, 94000 Créteil, France.

Received: 27 May 2019 Accepted: 11 December 2019

Published online: 19 December 2019

\section{References}

1. Detterbeck FC, Boffa DJ, Kim AW, Tanoue LT. The eighth edition lung Cancer stage classification. Chest. 2017;151(1):193-203.

2. Albain KS, Crowley JJ, LeBlanc M, Livingston RB. Survival determinants in extensive-stage non-small-cell lung cancer: the southwest oncology group experience. J Clin Oncol. 1991;9(9):1618-26.

3. De Pas TM, de Braud F, Catalano G, et al. Oligometastatic non-small cell lung cancer: a multidisciplinary approach in the positron emission tomographic scan era. Ann Thorac Surg. 2007;83(1):231-4.

4. Shultz DB, Filippi AR, Thariat J, Mornex F, Loo BW Jr, Ricardi U. Stereotactic ablative radiotherapy for pulmonary oligometastases and oligometastatic lung cancer. J Thorac Oncol. 2014;9(10):1426-33.
5. Group NM-AC. Chemotherapy in addition to supportive care improves survival in advanced non-small-cell lung cancer: a systematic review and meta-analysis of individual patient data from 16 randomized controlled trials. J Clin Oncol. 2008;26(28):4617-25.

6. Helou J, Thibault I, Poon I, et al. Stereotactic ablative radiation therapy for pulmonary metastases: histology, dose, and indication matter. Int J Radiat Oncol Biol Phys. 2017;98(2):419-27.

7. Gomez DR, Blumenschein GR Jr, Lee JJ, et al. Local consolidative therapy versus maintenance therapy or observation for patients with oligometastatic non-small-cell lung cancer without progression after firstline systemic therapy: a multicentre, randomised, controlled, phase 2 study. Lancet Oncol. 2016;17(12):1672-82.

8. Gomez DR, Niibe Y, Chang JY. Oligometastatic disease at presentation or recurrence for nonsmall cell lung cancer. Pulm Med. 2012;2012:396592.

9. De Ruysscher D, Wanders R, Hendriks LE, et al. Progression-free survival and overall survival beyond 5 years of NSCLC patients with synchronous Oligometastases treated in a prospective phase II trial (NCT 01282450). J Thorac Oncol. 2018;13(12):1958-61.

10. Lewis SL, Porceddu S, Nakamura N, et al. Definitive stereotactic body radiotherapy (SBRT) for Extracranial Oligometastases: an international survey of >1000 radiation oncologists. Am J Clin Oncol. 2017;40(4):418-22.

11. Collen C, Christian N, Schallier D, et al. Phase II study of stereotactic body radiotherapy to primary tumor and metastatic locations in oligometastatic nonsmall-cell lung cancer patients. Ann Oncol. 2014; 25(10):1954-9.

12. Griffioen $\mathrm{GH}$, Toguri $\mathrm{D}$, Dahele $\mathrm{M}$, et al. Radical treatment of synchronous oligometastatic non-small cell lung carcinoma (NSCLC): patient outcomes and prognostic factors. Lung Cancer. 2013;82(1):95-102.

13. lyengar $\mathrm{P}$, Kavanagh $\mathrm{BD}$, Wardak $\mathrm{Z}$, et al. Phase II trial of stereotactic body radiation therapy combined with erlotinib for patients with limited but progressive metastatic non-small-cell lung cancer. J Clin Oncol. 2014;32(34): 3824-30.

14. Hecht M, Zimmer L, Loquai C, et al. Radiosensitization by BRAF inhibitor therapy-mechanism and frequency of toxicity in melanoma patients. Ann Oncol. 2015;26(6):1238-44.

15. Stephans KL, Djemil T, Diaconu C, et al. Esophageal dose tolerance to hypofractionated stereotactic body radiation therapy: risk factors for late toxicity. Int J Radiat Oncol Biol Phys. 2014;90(1):197-202.

16. Chaft JE, Oxnard GR, Sima CS, et al. Disease flare after tyrosine kinase inhibitor discontinuation in patients with EGFR-mutant lung cancer and acquired resistance to erlotinib or gefitinib: implications for clinical trial design. Clin Cancer Res. 2011;17(19):6298-303.

17. Hu F, Xu J, Zhang B, et al. Efficacy of local consolidative therapy for Oligometastatic lung adenocarcinoma patients harboring epidermal growth factor receptor mutations. Clin Lung Cancer. 2019;20(1):e81-90.

18. Barlesi F, Mazieres J, Merlio JP, et al. Routine molecular profiling of patients with advanced non-small-cell lung cancer: results of a 1-year nationwide programme of the French cooperative thoracic intergroup (IFCT). Lancet. 2016;387(10026):1415-26.

19. Weickhardt AJ, Scheier B, Burke JM, et al. Local ablative therapy of oligoprogressive disease prolongs disease control by tyrosine kinase inhibitors in oncogene-addicted non-small-cell lung cancer. J Thorac Oncol. 2012;7(12):1807-14.

20. lyengar P, Wardak Z, Gerber DE, et al. Consolidative Radiotherapy for Limited Metastatic Non-Small-Cell Lung Cancer: A Phase 2 Randomized Clinical Trial. JAMA Oncol. 2018;4(1):e173501.

21. Palma DA, Olson RA, Harrow S, et al. Stereotactic ablative radiation therapy for the comprehensive treatment of Oligometastatic tumors (SABR-COMET): results of a randomized trial. Int J Radiat Oncol Biol Phys. 2018;102(3):S3-4.

22. Correction: Study protocol for the SARON trial: a multicentre, randomised controlled phase III trial comparing the addition of stereotactic ablative radiotherapy and radical radiotherapy with standard chemotherapy alone for oligometastatic non-small cell lung cancer. BMJ Open. 2019;9(5): e020690corr1

23. Conventional Care Versus Radioablation (Stereotactic Body Radiotherapy) for Extracranial Oligometastases - Full Text View - ClinicalTrials.gov [Internet]. https://clinicaltrials.gov/ct2/show/NCT02759783

24. Chang JY, Senan S, Paul MA, et al. Stereotactic ablative radiotherapy versus lobectomy for operable stage I non-small-cell lung cancer: a pooled analysis of two randomised trials. Lancet Oncol. 2015;16(6):630-7. 
25. Salama JK, Hasselle MD, Chmura SJ, et al. Stereotactic body radiotherapy for multisite extracranial oligometastases: final report of a dose escalation trial in patients with 1 to 5 sites of metastatic disease. Cancer. 2012;118(11): 2962-70.

26. Lester-Coll NH, Rutter CE, Bledsoe TJ, Goldberg SB, Decker RH, Yu JB. CostEffectiveness of Surgery, Stereotactic Body Radiation Therapy, and Systemic Therapy for Pulmonary Oligometastases. Int J Radiat Oncol Biol Phys. 2016; 95(2):663-672.

\section{Publisher's Note}

Springer Nature remains neutral with regard to jurisdictional claims in published maps and institutional affiliations.

Ready to submit your research? Choose BMC and benefit from:

- fast, convenient online submission

- thorough peer review by experienced researchers in your field

- rapid publication on acceptance

- support for research data, including large and complex data types

- gold Open Access which fosters wider collaboration and increased citations

- maximum visibility for your research: over $100 \mathrm{M}$ website views per year

At $\mathrm{BMC}$, research is always in progress.

Learn more biomedcentral.com/submissions 